\title{
Difference in Surface Roughness of Ethylene-Vinyl-Acetate Sheet before and after Application of Finishing Liquid
}

\author{
Mutsumi Takahashi ${ }^{*}$, Yogetsu Bando ${ }^{2}$ \\ ${ }^{1}$ Department of Physiology, School of Life Dentistry at Niigata, The Nippon Dental University, Niigata, Japan \\ ${ }^{2}$ Bando Dental Clinic, Ishikawa, Japan \\ Email: *mutsumit@ngt.ndu.ac.jp
}

How to cite this paper: Takahashi, M. and Bando, Y. (2018) Difference in Surface Roughness of Ethylene-Vinyl-Acetate Sheet before and after Application of Finishing Liquid. Materials Sciences and Applications, 9, 985-992.

https://doi.org/10.4236/msa.2018.913071

Received: November 1, 2018

Accepted: November 30, 2018

Published: December 3, 2018

Copyright () 2018 by authors and Scientific Research Publishing Inc. This work is licensed under the Creative Commons Attribution-NonCommercial International License (CC BY-NC 4.0). http://creativecommons.org/licenses/by-nc/4.0/ (c) (i) (8) Open Access

\begin{abstract}
Surface texture of the mouthguard affects the sense of adaptation in the athlete and further affects hygiene. Therefore, finish polishing is extremely important. The aim of this study was to investigate the difference in the surface roughness after finishing polishing of ethylene-vinyl-acetate (EVA) sheets and after application of the finishing liquid, and to evaluate its effectiveness. Total of 48 specimens of EVA $(3 \times 3 \mathrm{~mm})$ were divided into 4 groups according to polishing condition (control $=$ unpolished; condition $\mathrm{A}=$ Robinson-brush; condition $\mathrm{B}=$ Lisko-Fine, and condition $\mathrm{C}=$ Mouthguard-wheel). Polishing was performed at low speed by using a straight headpiece. The rotation speeds were 5000, 4000 and $6000 \mathrm{rpm}$ for condition A, B, and C, respectively. Next, a finishing liquid was applied to each specimen. For application, a cotton swab was used, and it was applied by three reciprocations. A non-contact surface shape measuring machine was used for measuring surface roughness; the measurement range is $1.65 \mathrm{~mm}$ and the resolution is 0.01 $\mathrm{nm}$. The arithmetic average height $(\mathrm{Sa})$ was measured. The differences in the surface roughness before and $15 \mathrm{~min}$ after the application of the finishing liquid were analyzed by two-way analysis of variance and Bonferroni's multiple comparison tests. Surface roughness of the specimen before application became coarse in the order of control, condition C, B and A, and Sa was about $0.20,1.98,2.92$, and $4.71 \mu \mathrm{m}$, respectively. The degree of reduction in roughness was about $1.0 \mu \mathrm{m}$ or more than each polished state in conditions $A$ and B. Condition $\mathrm{C}$ was not significantly different before and after application. No significant difference was observed between condition B and C after application. The results of this study showed that the surface roughness decreased due to the application of the finishing liquid when the surface roughness after finish polishing was about $2.0 \mu \mathrm{m}$ or more.
\end{abstract}




\section{Keywords}

Mouthguard, Ethylene-Vinyl-Acetate, Surface Roughness, Polishing Method, Finishing Liquid

\section{Introduction}

Mouthguards can reduce the risk and severity of sports-related injuries in many sports, but sheet material and thickness have a large effect on their efficacy and safety [1] [2] [3] [4] [5]. Mouthguards are available on the market or can be custom made, and there is a big difference between comfort and adaptation. Some reasons that athletes have cited for not using mouthguards include foreign body sensation, nauseous feeling, pronunciation disturbance and breathing disorder [6]. These problems can be caused by the thickness, occlusal state, setting position and form of the edge, but can be overcome by adjusting the mouthguard according to the athletes' oral condition. Therefore, it is recommended to use a custom-made mouthguard that is fabricated and adjusted according to the individual [1]. Custom-made mouthguards are fabricated by softening and vacuum/pressing various thermoplastic elastomers. Among these, ethylene vinyl acetate resin (EVA) has been shown to be a suitable material that possesses good impact force absorbing and dispersing ability and is inexpensive [7]. In general, the surface texture of an intra-oral apparatus affects hygiene factors, such as odor and coloring, in addition to sensory problems, such as wearing feeling and tongue feeling. The surface roughness of dental materials can directly influence bacterial adhesion, as microorganisms adhere to irregular surfaces more easily [8]. The long-term presence of microorganisms is a major cause of oral diseases such as gingivitis and dental caries. The presence of an oral infection during sports may have a negative impact on athletes [9]. Therefore, in order to keep the mouthguard sanitary and to improve the wearing feeling, the morphology of the edge of the mouthguard and the polish state are important. Polishing of the mouthguard material includes the use of silicone points and dedicated wheels, and dissolving the surface layer with an organic solvent, a torch or hot air. As for the polishing procedure, it is known that a poorly polished surface can induce the accumulation of microorganisms due to greater roughness [8] [10]. Almeida et al. [11] investigated whether thickness, color and polishing process influence the surface roughness of EVA sheets, and the amount of microorganisms that adhere to them. They found that polishing systems using hot-air burners were effective in decreasing the surface roughness without influencing the amount of adhered microorganisms. However, the effects of finishing liquids that increase the gloss and surface smoothness of mouthguards have not been investigated.

The aim of this study was to investigate the difference in the surface roughness after finish polishing of EVA sheets and after finishing liquid application, and to evaluate its effectiveness. 


\section{Materials and Methods}

The EVA sheets (Sports Mouthguard ${ }^{\circledR}, 4.0-\mathrm{mm}$-thick, clear; Keystone Dental Inc., Cherry Hill, NJ) were thermoplastified in a pressure molding machine (Durofomat ${ }^{\circledR}$, DreveDentamid GmbH Unna, Germany). Next, 48 specimens measuring $3 \times 3 \mathrm{~mm}$ were obtained [11] and divided into 4 groups according to polishing conditions; 1) unpolished (control), 2) polished using a Robinson-brush (No.11 soft, Buffalo Dental mfg. Co., Inc., Syosset, NY) (condition A), 3) polished using a Lisko-Fine (No.11 soft, Buffalo Dental mfg. Co., Inc., Syosset, NY) (condition B), and 4) polished using a Mouthguard-wheel (YAMAHACHI DENTAL MFG., CO., Aichi, Japan) (condition C). Polishing was performed at low speed by using a straight headpiece. The rotation speed was based on the maximum rotation speed specified by the manufacturer. Maximum rotational speeds were 5000, 4000 and $6000 \mathrm{rpm}$ for condition A, B, and C, respectively. After polishing, each specimen was cleaned in a sonic bath with distilled water for $5 \mathrm{~min}$ [11]. All specimens were prepared by one operator.

Next, a finishing liquid (Drufosoft ${ }^{\circledR}$ finishing liquid, DreveDentamid, GmbH, Unna, Germany) was applied to each specimen. For application, a cotton swab was used, and it was applied by three reciprocations using light pressure. A non-contact surface shape measuring machine (CCI HD-XL, Taylor Hobson, Leicester, UK) was used for measuring surface roughness; the measurement range is $1.65 \mathrm{~mm}$ and the resolution is $0.01 \mathrm{~nm}$. The arithmetic average height ( $\mathrm{Sa}$ ) was measured. The surface roughness before and $15 \mathrm{~min}$ after the application of the finishing liquid was compared. The means were obtained from the 3 measurements made in each specimen. Application of the finishing liquid and measurement were carried out for each specimen by one operator.

IBM SPSS 24.0 software (SPSS Japan Inc., Tokyo, Japan) was used for statistical analysis. The Shapiro-Wilk test for normality of distribution and Levene's test for homogeneity of variance were used to analyze the difference in the surface roughness of the EVA sheet before and after application of the finishing liquid. Normality and equality of variance were found for each item. All analyses were performed using two-way analysis of variance and Bonferroni's post-hoc test. Significance was set to $\mathrm{P}<0.05$, and the power was set to 0.8 for all analysis. Overall, a significant difference was considered to be present when both items were satisfied [12] [13].

\section{Results and Discussion}

Figure 1 shows surface texture images of the EVA sheet before and after application of the finishing liquid obtained by the non-contact surface shape measuring machine. Surface roughness of the specimen before application was in the order of control, condition C, B and A. The surface roughness of condition A, B and $\mathrm{C}$ tended to decrease after application of the finishing liquid.

Two-way ANOVA results for the differences in surface roughness of the EVA sheets before and after application of the finishing liquid are summarized in $\mathrm{Ta}$ - 
ble 1. Simple main effect test was carried out because both the main effect and the interaction between measurement time point and sheet processing condition were significant. Figure 2 shows the results of multiple comparison test for sheet surface roughness depending on measurement time points and sheet processing conditions. Sa before application increased in the order of control, condition C, $\mathrm{B}$ and $\mathrm{A}$, and a significant difference was observed among all conditions. Conditions A and B were lubricated by about $1.0 \mu \mathrm{m}$ or more due to the application of finishing liquid. Condition $\mathrm{C}$ was not significantly different between the measurement times. No significant difference was observed between conditions B and $\mathrm{C}$ after application.

Surface texture of the mouthguard affects the sense of adaptation in the athlete and further affects hygiene. Therefore, finish polishing is extremely important [11]. Reported methods of softening the surface layer include polishing with a silicone point, dissolution with an organic solvent or softening the surface layer with a torch. More recently, urethane-type points, spongy wheels, liquid polishing agents, and hot air burner have been used. It has also been reported that polishing systems associated with hot air burners were effective in reducing surface roughness [11].

The main materials used to fabricate mouthguards are EVA type elastomers, olefin type elastomers, and styrene type elastomers. In the polishing process, it is important to understand the material properties. In particular, the softening temperature of the sheet is important for proper molding timing, shape changes

Table 1. Results of two-way ANOVA for surface roughness

\begin{tabular}{cccccc}
\hline Source & SS & df & MS & F value & P value \\
\hline Measurement time point (A) & 12.141 & 1 & 12.141 & 74.293 & $<0.001^{\star *}$ \\
Processing condition (B) & 181.668 & 3 & 60.556 & 370.554 & $<0.001^{\star *}$ \\
A $\times$ B & 9.014 & 3 & 3.005 & 18.386 & $<0.001^{\star *}$ \\
Error & 14.381 & 88 & 0.163 & & \\
\hline
\end{tabular}

SS: sum of square; df: degree of freedom; MS: mean square. ${ }^{* *}$ : statistically significant, with $\mathrm{P}<0.01$.

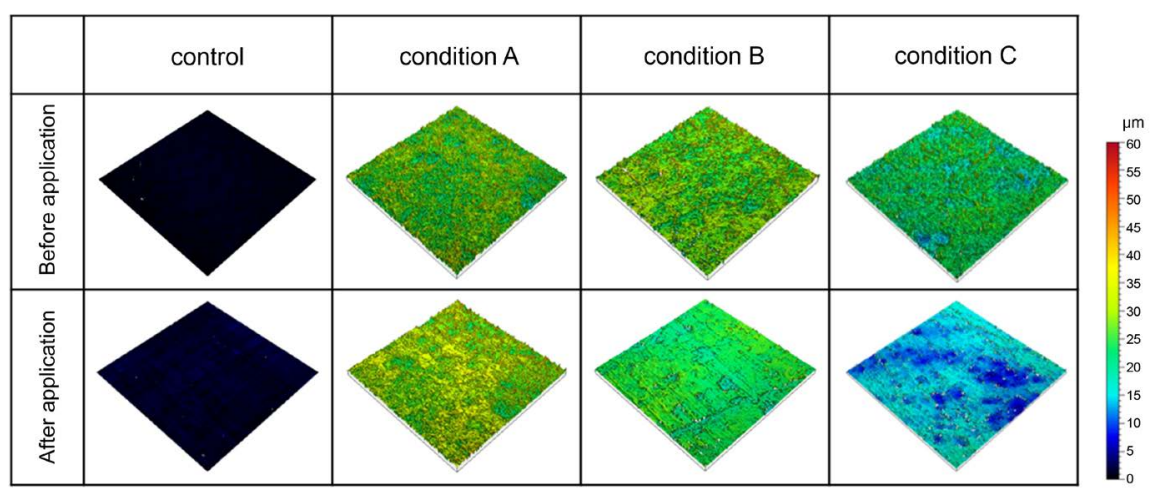

Figure 1. Surface texture image of EVA sheet by non-contact surface shape measuring machine. Measurement range; $0.83 \times 0.83 \mathrm{~mm}$, Objective lens; $\times 10$, Digital zoom; $\times 2$, Height scale; 0 - $60 \mathrm{~mm}$. 


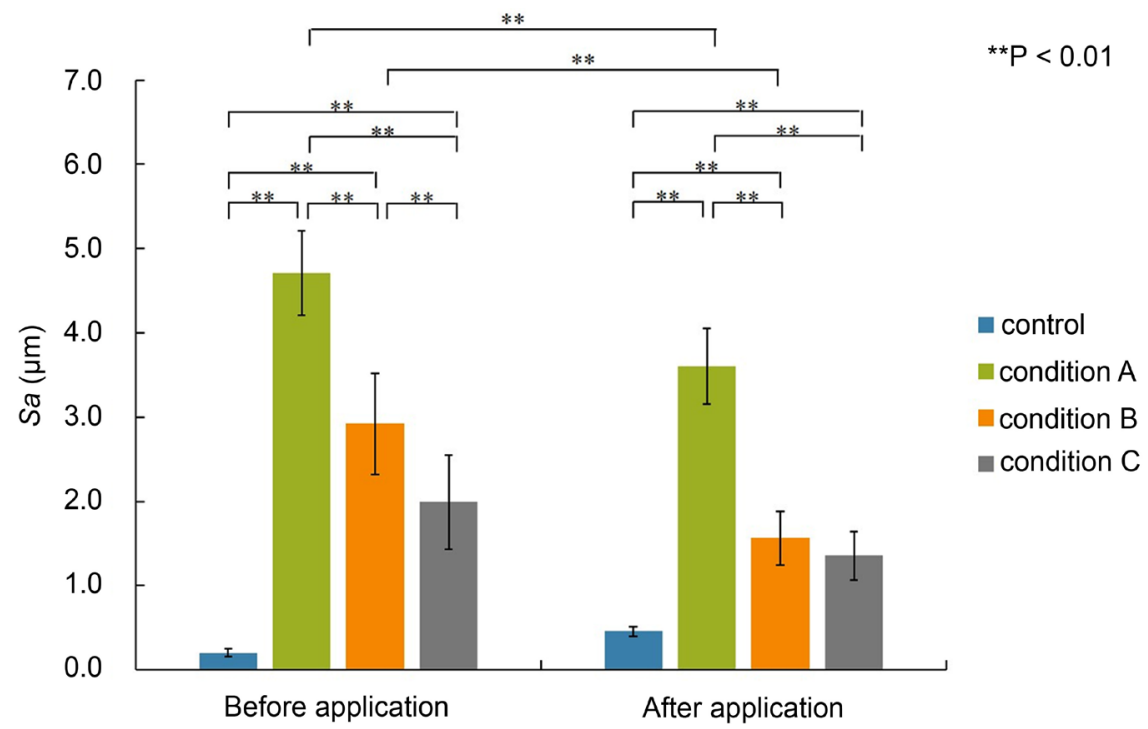

Figure 2. Comparison tests of surface roughness based on processing conditions.

after molding and operating steps during polishing. This is because overheating during molding leads to a reduction in shock absorbing ability after curing of the sheet. In addition, the influence of heat during shape modification/polishing (i.e., heat generation by rotating cutting tool or hot air burner) affects the adaptation of the mouthguard. The mouthguard sheet is stretched at molding, and stress can accumulate. This residual stress may be released by re-stimulation (i.e., occlusal pressure or reheat), which may lead to a reduction in adaptation of the mouthguard. Therefore, careful attention must be paid to the temperature changes during shape modification and polishing. Recently, a commercial finishing liquid used for the polishing stage of the mouthguard became available. However, the surface texture after application of the finishing liquid and its effectiveness after coating have not been reported. In this study, we investigated the effectiveness of finishing liquid application to the EVA sheet after finish polishing with various wheels.

There are few reports quantitatively investigating the surface properties of mouthguards, they have been evaluated using a gloss level measuring device and a digital portable surface roughness tester meter [11]. In this study, the arithmetic average height ( $S a$ ) was used to evaluate the surface texture of the mouthguard [14] [15] [16]. $S a$ is a representative three-dimensional surface texture parameter, and is obtained by expansion the surface roughness $(R a)$ of the two-dimensional parameter into three dimensions. This index represents the average value of the absolute value of the difference in height between each point (peak height and valley depth) with respect to the average of the surface. This makes it possible to evaluate the anisotropy of the surface skin, which cannot be digitized by two-dimensional parameters. The influence of one scratch on the measured value becomes very small, and it is a feature that stable measurement results can be obtained [17]. It is predicted that the presence or absence and ex- 
tent of spikes are likely to influence the measured values when specimen processing is hand-operated, as in this study. In the surface texture image shown in Figure 1, the valley portion serves as a reference surface and the height difference of the spike was scaled, so it was difficult to compare among the conditions. For this reason, we considered evaluation by $S a$ to be appropriate for comparison of surface properties in this study.

As a result of this study, $S a$ of condition A, B and C tended to decrease after application of finishing liquid, but no differences were observed between the measurement times for condition C. Namely, the surface roughness decreased due to the application of the finishing liquid when the surface roughness after finish polishing was about $2.0 \mu \mathrm{m}$ or more. It was also revealed that the degree of reduction in roughness was about $1.0 \mu \mathrm{m}$ or more than each polished state. In addition, because $S$ a after application in conditions A, B and C showed significant differences with control, it was revealed that lubricity as high as the control cannot be obtained even if finishing liquid is applied after polishing using various wheels. In the future, it will be necessary to compare with finishing treatments with the hot air burner and differences when applying other finishing liquids. We also plan to investigate the relationship among residual stress at molding, released stress by reheating, and adaptation of the mouthguard.

\section{Conclusion}

In this study, we investigated the difference in surface roughness after finishing polishing of EVA sheets and after finishing liquid application, and to evaluate its effectiveness. As the results suggested that when the surface roughness after polishing was about $2.0 \mu \mathrm{m}$ or more, the surface roughness decreased by about $1.0 \mu \mathrm{m}$ or more after application of finishing liquid. Additionally, even if finishing liquid was applied after polishing, lubricity comparable to the original sample was not obtained.

\section{Acknowledgements}

The authors thank Mr. Haruhiko Ishii and Mr. Taisuke Sato for advice in the preparation of the manuscript.

\section{Conflicts of Interest}

The authors report no conflict of interest. This study was supported by Nippon Dental University Intramural Research Fund.

\section{References}

[1] Verissimo, C., Costa, P.V., Santos-Filho, P.C., Tantbirojn, D., Versluis, A. and Soares, C.J. (2016) Custom-fitted EVA Mouthguards: What Is the Ideal Thickness? A Dynamic Finite Element Impact Study. Dental Traumatology, 32, 95-102. https://doi.org/10.1111/edt.12210

[2] Gialain, I.O., Coto, N.P., Driemeier, L., Noritomi, P.Y. and Dias, R.B. (2016) A 
Three-Dimensional Finite Element Analysis of the Sports Mouthguard. Dental Traumatology, 32, 409-415. https://doi.org/10.1111/edt.12265

[3] Bochnig, M.S., Oh, M.J., Nagel, T., Ziegler, F. and Jost-Brinkmann, P.G. (2017) Comparison of the Shock Absorption Capacities of Different Mouthguards. Dental Traumatology, 33, 205-213. https://doi.org/10.1111/edt.12324

[4] Gawlak, D., Mańka-Malara, K., Mierzwińska-Nastalska, E., Gieleta, R., Kamiński, T. and Łuniewska, M. (2017) A Comparison of Impact Force Reduction by Polymer Materials Used for Mouthguard Fabrication. Acta of Bioengineering and Biomechanics, 19, 89-95.

[5] Tribst, J.P.M., de Oliveira, Dal Piva, A.M., Borges, A.L.S. and Bottino, M.A. (2018) Influence of Custom-Made and Stock Mouthguard Thickness on Biomechanical Response to a Simulated Impact. Dental Traumatology, 34, 429-437.

https://doi.org/10.1111/edt.12432

[6] Gawlak, D., Mierzwińska-Nastalska, E., Mańka-Malara, K. and Kamiński, T. (2015) Assessment of Custom and Standard, Self-Adapted Mouthguards in Terms of Comfort and Users Subjective Impressions of Their Protective Function. Dental Traumatology, 31, 113-117. https://doi.org/10.1111/edt.12132

[7] Coto, N.P., Brito, e Dias, R.B., Costa, R.A, Antoniazzi, T.F. and Carvalho, E.P. (2007) Mechanical Behavior of Ethylene Vinyl Acetate Copolymer (EVA) Used for Fabrication of Mouthguards and Interocclusal Splints. Brazilian Dental Journal, 18, 324-328. https://doi.org/10.1590/S0103-64402007000400010

[8] Kawai, K., Urano, M. and Ebisu, S. (2000) Effect of Surface Roughness of Porcelain on Adhesion of Bacteria and Their Synthesizing Glucans. The Journal of Prosthetic Dentistry, 86, 664-667. https://doi.org/10.1067/mpr.2000.107442

[9] Needleman, I., Ashley, P., Petrie, A., Fortune, F., Turner, W., Jones, J., Niggli, J., Engebretsen, L., Budgett, R., Donos, N., Clough, T. and Porter, S. (2013) Oral Health and Impact on Performance of Athletes Participating in the London 2012 Olympic Games: A Cross-Sectional Study. Journal of Sports Medicine, 47, 1054-1058. https://doi.org/10.1136/bjsports-2013-092891

[10] Leal, A., Paula, A., Ramalho, A., Esteves, M., Ferreira, M.M. and Carrilho, E. (2015) Roughness and Microhardness of Composites after Different Bleaching Techniques. Journal of Applied Biomaterials \& Functional Materials, 13, e381-e388. https://doi.org/10.5301/jabfm.5000239

[11] Almeida, M.H., Ceschim, G.V., Ioriom N.L.P.P., Póvoa, H.C.C., Cajazeira, M.R.R., Guimarães, G.S, Antunes, L.S. and Antunes, L.A.A. (2018) Influence of Thickness, Color, and Polishing Process of Ethylene-Vinyl-Acetate Sheets on Surface Roughness and Microorganism Adhesion. Dental Traumatology, 34, 51-57. https://doi.org/10.1111/edt.12374

[12] Takahashi, M. and Bando, Y. (2018) Effect of the Anteroposterior Position of the Model on Fabricated Mouthguard Thickness: Part 2 Influence of Sheet Thickness and Material. Dental Traumatology, 34, 370-377. https://doi.org/10.1111/edt.12423

[13] Takahashi, M. and Bando, Y. (2018) Thermoforming Method to Effectively Maintain Mouthguard Thickness: Effect of Moving the Model Position Just before Vacuum Formation. Dental Traumatology, in press.

https://doi.org/10.1111/edt.12447

[14] Fawzy, A.S., Amer, M.A. and El-Askary, F.S. (2008) Sodium Hypochlorite as Dentin Pretreatment for Etch-and-Rinse Single-Bottle and Two-Step Self-Etching Adhesives: Atomic Force Microscope and Tensile Bond Strength Evaluation. The Journal of Adhesive Dentistry, 10, 135-144. 
[15] Sul, Y.T., Kang, B.S., Johansson, C., Um, H.S., Park, C.J. and Albrektsson, T. (2009) The Roles of Surface Chemistry and Topography in the Strength and Rate of Osseointegration of Titanium Implants in Bone. Journal of Biomedical Materials Research Part A, 89, 942-950. https://doi.org/10.1002/jbm.a.32041

[16] Koshihara, T., Hara, M., Sato, T., Hayashibara, T., Masuda, T. and Shinya, A. (2016) Evaluation of the Surface Texture of CAD/CAM-Produced Crowns among Various Types of CAD/CAM Milling Systems. The Shikwa Gakuho, 116, 149-153. (In Japanese)

[17] Olympus Scientific Solutions Americas Corp. Height Parameters (Amplitude Mean in the Height Direction).

https://www.olympus-ims.com/en/knowledge/metrology/roughness/3d_parameter/ 